\title{
Association of high-sensitivity C-reactive protein with de novo major depression
}

Julie A. Pasco, Geoffrey C. Nicholson, Lana J. Williams, Felice N. Jacka, Margaret J. Henry, Mark A. Kotowicz, Hans G. Schneider, Brian E. Leonard and Michael Berk

\section{Background}

Although there is cross-sectional evidence that changes in the immune system contribute to the pathophysiology of depression, longitudinal data capable of elucidating cause and effect relationships are lacking.

\section{Aims}

We aimed to determine whether subclinical systemic inflammation, as measured by serum high-sensitivity C-reactive protein (hsCRP) concentration, is associated with an increased risk of de novo major depressive disorder.

\section{Method}

Major depressive disorder was diagnosed using a clinical interview (SCID-I/NP). This is a retrospective cohort study; from a population-based sample of 1494 randomly selected women recruited at baseline during the period 1994-7, 822 were followed for a decade and provided measures of both exposure and outcome. Of these women, 644 (aged 20-84 years) had no prior history of depression at baseline and were eligible for analysis.

\section{Results}

During 5827 person-years of follow-up, 48 cases of de novo major depressive disorder were identified. The hazard ratio (HR) for depression increased by $44 \%$ for each standard deviation increase in log-transformed hsCRP (In-hsCRP) $(\mathrm{HR}=1.44,95 \% \mathrm{Cl} 1.04-1.99)$, after adjusting for weight, smoking and use of non-steroidal anti-inflammatory drugs. Further adjustment for other lifestyle factors, medications and comorbidity failed to explain the observed increased risk for depression.

\section{Conclusions}

Serum hsCRP is an independent risk marker for de novo major depressive disorder in women. This supports an aetiological role for inflammatory activity in the pathophysiology of depression.

\section{Declaration of interest}

M.B. has received grant/research support from the Stanley Medical Research Foundation, MBF, National Health and Medical Research Council, Beyond Blue, Geelong Medical Research Foundation, Bristol-Myers Squibb, Eli Lilly, GlaxoSmithKline, Organon, Novartis, Mayne Pharma, Servier and AstraZeneca. He has been a paid consultant for AstraZeneca, Bristol-Myers Squibb, Eli Lilly, GlaxoSmithKline, Janssen-Cilag, Lundbeck and Pfizer, and a paid speaker for AstraZeneca, Bristol-Myers Squibb, Eli Lilly, GlaxoSmithKline, Janssen-Cilag, Lundbeck, Organon, Pfizer, Sanofi Synthelabo, Solvay and wyeth.
For nearly two decades it has been recognised that the immune system plays a role in depression. ${ }^{1}$ Systemic immune activation has been documented in major depression, with reports of increased levels of pro-inflammatory cytokines ${ }^{2-4}$ and changes in the acute phase protein response, notably enhancement of positive and diminution of negative acute phase proteins. ${ }^{5,6} \mathrm{C}$-reactive protein (CRP) is a positive acute response protein that marks systemic inflammation. ${ }^{7,8}$ Elevated levels of circulating CRP have been found in depression in both clinical and population studies. ${ }^{9-14}$ This literature, however, stems from cross-sectional association data that are unable to clarify whether systemic inflammation precedes the onset of depressive symptoms or occurs as part of the somatic manifestations of the depressive phenotype.

There is some evidence to suggest that systemic inflammation might be a risk factor for depression. In animal models, systemic administration of pyrogens to mice induces sickness behaviour analogous to depressive symptomatology in humans. ${ }^{15}$ Depression is commonly reported among human patients following exposure to cytokine-based immunotherapy, as seen in the treatment with interleukin-2 of metastatic renal cell carcinoma and metastatic melanoma, ${ }^{16-18}$ and in the treatment with interferon- $\alpha$ of patients with hepatitis C. ${ }^{19}$ To date, findings from two prospective studies suggest that systemic inflammation might precede the development of depressive symptoms. ${ }^{20,21}$ However, it is unclear to what extent these results can be generalised beyond the elderly population. ${ }^{22}$

We hypothesised that circulating inflammatory markers might be associated with an increased risk for depression across the full adult-age spectrum. Although CRP levels are traditionally only elevated in severe inflammation, newer assays with improved sensitivity (high-sensitivity CRP, hsCRP) are able to measure CRP in healthy individuals, permitting an exploration of the posited association between subclinical systemic inflammation and risk of depression. We aimed to investigate serum hsCRP concentration as a risk marker for major depressive disorder in women, using longitudinal data extending over a decade.

\section{Method}

\section{Study design and participants}

This project was conducted as part of the Geelong Osteoporosis Study (GOS), a population-based study originally designed for monitoring the epidemiology of osteoporosis, but more recently expanded to examine psychiatric illness and other health disorders. The target population was the Barwon Statistical Division in south-eastern Australia and the sample was randomly selected from the Australian Commonwealth electoral roll. All women listed on the electoral roll for the study region fulfilled the inclusion criteria. Exclusion criteria included inability to provide informed consent, contact failure and death. ${ }^{23}$ A cohort of 1494 women recruited into the GOS during the period 1994-7 has been prospectively followed for a decade. Collection of serum, questionnaire data and clinical measures was performed concurrently at baseline during the period 1994-7. During the period 2004-7, a total of 857 women participated in a psychiatric assessment and of these, 822 women also provided serum for 
biochemical analysis and were thus included in this retrospective cohort study. Written, informed consent was obtained from all participants. The Human Research Ethics Committee, Barwon Health, approved the study.

\section{Measurement of exposure variables}

Serum samples were collected in the morning following an overnight fast and stored at $-80^{\circ} \mathrm{C}$ until batch analysis. Serum hsCRP was measured by the Roche immunoturbidimetric 'CRP' and 'C-reactive protein (latex) high sensitivity' methods. Specimens were initially analysed using the high-sensitivity assay, which has a range of $0.1-20 \mathrm{mg} / \mathrm{l}$. Specimens with results above $20 \mathrm{mg} / \mathrm{l}$ were re-analysed using the CRP assay, which has a range of $3-480 \mathrm{mg} / \mathrm{l}$. The long-term inter-assay coefficient of variation is $<10 \%$ at $1 \mathrm{mg} / \mathrm{l}$ and $<5 \%$ at $5 \mathrm{mg} / \mathrm{l}$.

Height and weight were measured to the nearest $0.1 \mathrm{~cm}$ and $0.1 \mathrm{~kg}$ respectively, and body mass index (BMI) calculated in $\mathrm{kg} / \mathrm{m}^{2}$. Waist circumference was measured in a horizontal plane with a narrow, non-elastic tape measure. Self-reported details of medication use and lifestyle were documented by questionnaire. Cigarette smoking was recorded as never, past or current. Alcohol consumption was recognised if alcohol was consumed daily. Activity level was described as very active or active if vigorous or light exercise was performed regularly; otherwise, individuals were classified as sedentary. Socioeconomic status was ascertained using Socio-Economic Indexes for Areas scores based on 1996 census data from the Australian Bureau of Statistics. These data were used to derive an index of relative socioeconomic disadvantage (IRSD) that was categorised into five groups, according to quintiles of IRSD for the study region. Medication use was classified as current if used regularly at the time of assessment for non-steroidal anti-inflammatory drugs (NSAIDs; including aspirin), oral glucocorticoids, antidepressants, oral contraceptives and hormone therapy. Exposure to diseases, including pernicious anaemia, cancer and systemic lupus erythematosus, was documented by self-report. Cases of rheumatoid arthritis were identified from specialist registers in the region.

\section{Measurement of outcome}

The Structured Clinical Interview for DSM-IV-TR Research Version, Non-patient edition (SCID-I/NP) ${ }^{24}$ was used to identify women with a lifetime history of major depressive disorder and to determine age at onset. Trained personnel who were masked to biochemical and questionnaire data conducted the psychiatric interviews.

\section{Statistics}

Standard descriptive statistics were used to characterise participants. Serum hsCRP concentrations were natural log transformed (ln-hsCRP) to normalise the data before statistical analysis. Participants were grouped into tertiles of hsCRP for descriptive purposes. Two major analyses were performed.

High-sensitivity CRP and rate of major depressive disorder

Based on data from all 822 women, Poisson regression models were used to estimate the rate of diagnosis for each standard deviation increase in ln-hsCRP after adjusting for age, anthropometry, and demographic, health and lifestyle factors. Models were also tested for interaction terms. Rate ratios (RR) are expressed together with $95 \%$ confidence intervals (CI).

High-sensitivity CRP and risk for de novo major depressive disorder One hundred and seventy-eight individuals were not included in this analysis because they had experienced an episode of major depressive disorder prior to baseline or within the first year after baseline. The group of 644 eligible participants was followed from baseline until a first episode of depression or until the end of the 10 -year follow-up period. The association between baseline serum hsCRP (expressed in standard deviation units) and the development of de novo major depressive disorder was examined using Cox proportional hazards regression models, using age as the time axis and adjusting for confounding variables. The advantage of using age as the time axis is that it permits the baseline hazard to change as a function of age, thereby accounting for any confounding effects of age. ${ }^{25}$ The proportional hazards assumptions were checked using Schoenfeld residuals before and after adjusting for confounders. Statistical analyses were performed using Stata (release 9.0, StataCorp, College Station, Texas, USA) and Minitab (version 15; Minitab, State College, Pennsylvania, USA) for Windows.

\section{Results}

\section{High-sensitivity CRP and rate of major depressive disorder}

The distribution of hsCRP in this population was positively skewed with a median value of $1.91 \mathrm{mg} / \mathrm{l}$ (interquartile range, $\mathrm{IQR}=0.88-3.98)$. Few women $(54 / 822,6.6 \%)$ had hsCRP values greater than $10 \mathrm{mg} / \mathrm{l}$, indicating an acute inflammatory response. Participant characteristics are listed in Table 1. Serum ln-hsCRP

\begin{tabular}{|c|c|}
\hline & All participants \\
\hline Participants, $n$ & 822 \\
\hline Serum hsCRP, mg/l: median (IQR) & $1.88(0.88-3.98)$ \\
\hline Serum albumin, g/l: mean (s.d.) & $84.1(12.7)$ \\
\hline Age, years: median (IQR) & $47.0(35.0-60.0)$ \\
\hline Weight, kg: mean (s.d.) & $69.3(14.2)$ \\
\hline Height, cm: mean (s.d.) & $161.5(6.2)$ \\
\hline Body mass index, kg/m²: mean (s.d.) & $26.6(5.5)$ \\
\hline Waist circumference, cm: median (IQR) & $82(74-91)$ \\
\hline $\begin{array}{l}\text { Socioeconomic status, } n \text { (\%) } \\
\text { Quintile } 1 \text { (low) } \\
\text { Quintile } 2 \\
\text { Quintile } 3 \\
\text { Quintile } 4 \\
\text { Quintile } 5\end{array}$ & $\begin{array}{l}140(17.0) \\
167(20.3) \\
179(31.8) \\
151(18.4) \\
185(22.5)\end{array}$ \\
\hline $\begin{array}{l}\text { Smoking, } n(\%) \\
\text { Never } \\
\text { Past } \\
\text { Current }\end{array}$ & $\begin{array}{l}500(60.8) \\
204(24.8) \\
118(14.4) \\
\end{array}$ \\
\hline $\begin{array}{l}\text { Physical activity, } n \text { (\%) } \\
\text { Very active } \\
\text { Active } \\
\text { Sedentary }\end{array}$ & $\begin{array}{l}103(12.5) \\
541(65.8) \\
178(21.7) \\
\end{array}$ \\
\hline Alcohol consumed daily, $n$ (\%) & $64(7.8)$ \\
\hline NSAID use, $n(\%)$ & $144(17.5)$ \\
\hline Oral glucocorticoid use, $n$ (\%) & $7(0.9)$ \\
\hline Antidepressant use, $n$ (\%) & $33(4.0)$ \\
\hline Oral contraceptive use, $n$ (\%) & $132(16.1)$ \\
\hline Hormone therapy, $n$ (\%) & $106(12.9)$ \\
\hline Pernicious anaemia, $n$ (\%) & $22(2.7)$ \\
\hline Cancer, $n$ (\%) & $45(5.5)$ \\
\hline Rheumatoid arthritis, $n$ (\%) & $2(0.2)$ \\
\hline Systemic lupus erythematosus, $n$ (\%) & $2(0.2)$ \\
\hline Past major depression, $n$ (\%) & $134(16.3)$ \\
\hline
\end{tabular}


was weakly correlated with age $(r=0.1, P=0.001)$, and moderately correlated with all indices of adiposity, including weight, BMI and waist circumference $(r=0.4,0.5$ and 0.5 respectively, all $P<0.001$ ), which persisted after adjusting for age (all $P<0.001$ ). In multivariable models adjusted for age and weight, lifestyle factors associated with increased mean ln-hsCRP included physical inactivity (sedentary $28 \%$ greater than active/very active) and use of oral contraceptives or hormone therapy $(173 \%$ and $25 \%$ greater than non-users respectively) (all $P<0.05$ ). The mean ln-hsCRP for NSAID users was also greater than for non-users.

In total, 151 women had at least one major depressive episode during 8090 person-years of follow-up and 671 remained depression-free. Those who experienced depression were younger (median 41.0 years, IQR $=33.0-52.0$ v. 49.0 years, IQR $=36.0$ $62.0 ; P<0.001)$, more were current smokers $(n=35,23.2 \% v$. $n=83,12.4 \% ; P=0.001)$ and users of antidepressants $(n=11$, $7.3 \% v \cdot n=22,3.3 \% ; P=0.023)$, and more had a history of major depressive disorder $(n=103,68.2 \%$ v. $n=31,4.6 \% ; P<0.001)$. The rate of major depressive disorder was 18.7 per 1000 personyears (95\% CI 15.9-21.9). For each standard deviation increase in $\ln$-hsCRP, the rate of depression increased by $18 \%$, after adjusting for age, weight, use of NSAIDs and past major depressive disorder ( $\mathrm{RR}=1.18,95 \%$ CI $0.99-1.42, P=0.069$ ). None of the other anthropometric, demographic, medication or lifestyle factors were identified as confounders.

\section{High-sensitivity CRP and risk for de novo major depressive disorder}

Participant characteristics categorised into tertiles of hsCRP are shown in Table 2. The median concentration of hsCRP increased with weight, $\mathrm{BMI}$ and waist circumference, and those in the low tertile of hsCRP $(<1.12 \mathrm{mg} / \mathrm{l})$ were younger, more likely to be physically active and not to use oral contraceptives, and less likely to be socially disadvantaged. There were 48 cases of de novo major depressive disorder identified over 5827 person-years of follow-up. The unadjusted hazard ratio for major depressive disorder increased by $41 \%$ for each standard deviation increase in $\ln$-hsCRP (HR $=1.41,95 \%$ CI $1.07-1.86, P=0.015)$. The Kaplan-Meier survival plot (Fig. 1) shows that the probability of remaining depression-free was lowest for women in the upper hsCRP tertile $(>2.97 \mathrm{mg} / \mathrm{l})$ and highest for those in the lowest tertile. Multivariable models developed sequentially by adjusting for potential confounders included contributions from ln-hsCRP, weight, current smoking and use of NSAIDs. Thus, for each standard deviation increase in $\ln$-hsCRP there was an independent $44 \%$ increase in risk for major depressive disorder (adjusted $\mathrm{HR}=1.44,95 \%$ CI 1.04-1.99, $P=0.026$ ). Further adjustment for lifestyle factors, comorbid disease and use of other medications (oral contraceptives or hormone therapy) failed to explain the observed increased risk for depression.

Table 2 Baseline characteristics for participants categorised into tertiles of high-sensitivity C-reactive protein (hSCRP)

\begin{tabular}{|c|c|c|c|c|}
\hline & \multicolumn{4}{|c|}{ hsCRP $^{a}$} \\
\hline & Tertile 1 (low) & Tertile 2 (mid) & Tertile 3 (high) & $P$ \\
\hline $\begin{array}{l}\text { Participants, } n \\
\text { Serum hsCRP mg/l: median (IOR) }\end{array}$ & $\begin{array}{c}215 \\
0.62(0.36-0.89)\end{array}$ & $\begin{array}{c}214 \\
191(146-240)\end{array}$ & $\begin{array}{c}215 \\
521(385-904)\end{array}$ & -0001 \\
\hline Serum albumin, g/l: mean (s.d.) & $41.5(2.7)$ & $40.8(3.0)$ & $40.1(3.2)$ & $<0.001$ \\
\hline Age, years: median (IQR) & $44.1(34.6-58.2)$ & $52.6(36.1-64.7)$ & $50.2(35.8-62.6)$ & 0.01 \\
\hline Weight, kg: mean (s.d.) & $62.0(8.8)$ & $69.4(11.4)$ & $75.7(16.5)$ & $<0.001$ \\
\hline Height, cm: mean (s.d.) & $162.0(5.8)$ & $161.7(6.7)$ & $160.4(6.1)$ & 0.02 \\
\hline Body mass index, $\mathrm{kg} / \mathrm{m}^{2}$ : mean (s.d.) & $23.7(3.3)$ & $26.6(4.3)$ & $29.4(6.4)$ & $<0.001$ \\
\hline Waist circumference, cm: median (IQR) & $76(71-82)$ & $84(77-91)$ & $89(80-101)$ & $<0.001$ \\
\hline Socioeconomic status, $n$ (\%) & & & & 0.001 \\
\hline Quintile 1 (low) & $19(8.8)$ & $46(21.5)$ & $47(21.9)$ & \\
\hline Quintile 2 & $40(18.6)$ & $33(15.4)$ & $51(23.7)$ & \\
\hline Quintile 3 & $48(22.3)$ & $52(24.3)$ & $42(19.5)$ & \\
\hline Quintile 4 & $49(22.8)$ & $31(14.5)$ & $37(17.2)$ & \\
\hline Quintile 5 & $59(27.4)$ & $52(24.3)$ & $38(17.7)$ & \\
\hline Smoking, $n(\%)$ & & & & 0.791 \\
\hline Never & $141(65.6)$ & $130(60.8)$ & $130(60.5)$ & \\
\hline Past & $50(23.3)$ & $54(25.2)$ & $56(26.1)$ & \\
\hline Current & $24(11.2)$ & $30(14.0)$ & $29(13.5)$ & \\
\hline Physical activity, $n$ (\%) & & & & $<0.001$ \\
\hline Very active & $39(18.1)$ & $27(12.6)$ & $16(7.4)$ & \\
\hline Active & $148(68.8)$ & $132(61.7)$ & $136(63.3)$ & \\
\hline Sedentary & $28(13.0)$ & $55(25.7)$ & $63(29.3)$ & \\
\hline Alcohol consumed daily, $n$ (\%) & $22(10.2)$ & $16(7.5)$ & $15(7.0)$ & 0.417 \\
\hline NSAID use, $n(\%)$ & $33(15.4)$ & $33(15.4)$ & $50(23.3)$ & 0.050 \\
\hline Oral glucocorticoid use, $n$ (\%) & $2(0.9)$ & $2(0.9)$ & $2(0.9)$ & 1.0 \\
\hline Antidepressant use, $n(\%)$ & $4(1.9)$ & $6(2.8)$ & $6(2.8)$ & 0.772 \\
\hline Oral contraceptive use, $n(\%)$ & $17(7.9)$ & $41(19.2)$ & $48(22.3)$ & $<0.001$ \\
\hline Hormone therapy, $n$ (\%) & $16(7.4)$ & $25(11.7)$ & $29(13.5)$ & 0.118 \\
\hline Pernicious anaemia, $n(\%)$ & $11(5.1)$ & $2(0.9)$ & $2(0.9)$ & \\
\hline Cancer, $n$ (\%) & $4(1.9)$ & $16(7.5)$ & $14(6.5)$ & \\
\hline Rheumatoid arthritis, $n$ (\%) & 0 & $1(0.5)$ & $1(0.5)$ & \\
\hline Systemic lupus erythematosus, $n(\%)$ & $1(0.5)$ & $1(0.5)$ & 0 & \\
\hline
\end{tabular}




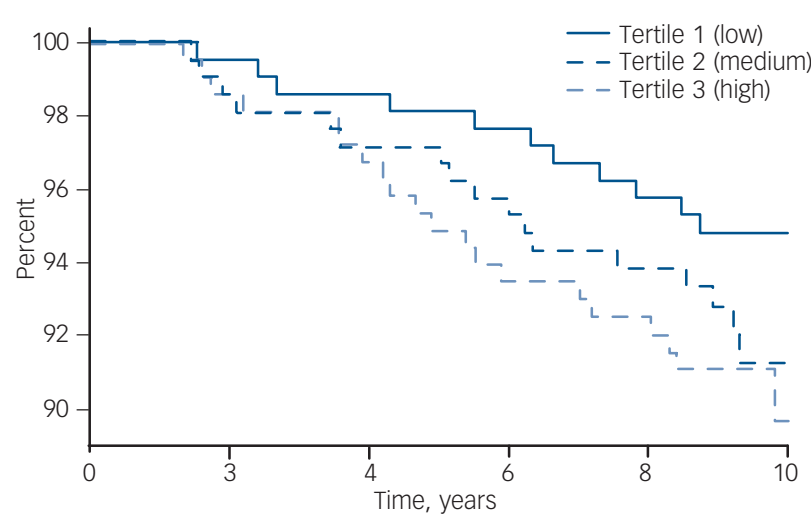

Fig. 1 Survival plot (Kaplan-Meier) showing the probability of remaining free of de novo major depressive disorder for women stratified into tertiles of hsCRP. The concentration of hsCRP in each tertile is: low, $<1.12 \mathrm{mg} / \mathrm{l}$; mid, $1.12-2.97 \mathrm{mg} / \mathrm{l}$; and high, $>2.97 \mathrm{mg} / \mathrm{l}$.

\section{Discussion}

To our knowledge, this is the first study to investigate hsCRP as a risk marker for de novo major depressive disorder in a populationbased, longitudinal study spanning the full adult range. We report an apparent $44 \%$ increase in the risk for major depressive disorder for each standard deviation increase in ln-hsCRP among women who had never experienced a prior episode of depression. This association was not explained by differences in weight, lifestyle, medication use or comorbid disease. These findings were supported by a trend for a positive association between circulating hsCRP levels and the rate of major depression over the ensuing decade.

The moderate correlations we report between circulating CRP levels and indices of adiposity, both general and visceral, have been documented previously. ${ }^{26-30}$ Excess body fat enhances circulating CRP and may be considered a state of low-grade inflammation as adipose tissue produces interleukin- 6 and tumor necrosis factor- $\alpha$ and is involved in the regulation of other cytokines. ${ }^{28}$ Overweight and obesity are common in women with major depression. ${ }^{31-33}$ The impact of obesity as a confounder in the relationship between hsCRP and major depressive disorder was thus identified and addressed by including weight as a covariate in the regression models. The association between hsCRP and depression was sustained, albeit attenuated, after adjusting for weight. Similar patterns were observed by substituting weight with other indices of adiposity such as BMI or waist circumference. Consequently, the relationship between hsCRP and major depression was deemed independent of adiposity.

C-reactive protein is regarded as a key indicator of an inflammatory process. ${ }^{34}$ Several cross-sectional studies have examined the association between CRP and depression in population-based samples. Most reported a positive association, ${ }^{10,11,13,14}$ one was negative, ${ }^{35}$ and another found only a gender-specific association in men. ${ }^{12}$ Although a meta-analysis of these studies concluded that prospective trials are necessary to address issues of causality, ${ }^{36}$ these data corroborate those from prospective studies of two elderly populations for which raised markers of systemic inflammation pre-dated the onset of depressive symptoms..$^{20,21}$

An acute phase immune response might operate to increase the risk of depression via multiple pathways. Both early-life stress (e.g. social isolation) and late-life stress (e.g. chronic mild stress) increase both peripheral and central levels of pro-inflammatory cytokines. The ability of stress to operate as a risk factor for depression is widely accepted. Inflammation increases oxidative stress, and oxidative stress is increasingly regarded as an operative mechanism in depression. ${ }^{37,38}$ Oxidative stress disrupts lipid membranes via peroxidation, and proteins via carbonylation, which are described in depression. ${ }^{39,40}$ Pro-inflammatory cytokines also affect serotonin neurotransmission. Interferon gamma reduces the production of serotonin by converting its precursor, tryptophan, to tryptophan catabolites (TRYCATS) such as kynurine. ${ }^{41}$ These are potentially anxiogenic and neurotoxic.

\section{Strengths and limitations}

There are several strengths and potential weaknesses in our study. Although acknowledging that depression is a heterogeneous disorder, we utilised the reference-standard tool (SCID) for the clinical assessment of major depressive disorder. The longitudinal nature of the design and the length of the follow-up period are other key strengths. Given that elevated hsCRP is one of many potential operative risks for depression, such vulnerability may only be reliably demonstrated over an extended timeframe. However, recall limitations may have affected our ability to accurately diagnose the age at onset of depressive episodes. Moreover, as in all observational studies, there may be unrecognised confounding. Physical activity, smoking and alcohol use were explored as concomitant lifestyle factors with a potential for confounding because of their previously reported influence on both CRP concentration ${ }^{30}$ and the risk for depression. ${ }^{42,43}$ Our previous demonstration of an association between tobacco smoking and increased risk for major depressive disorder ${ }^{42}$ may have a multifactorial basis including dysregulation of the dopaminergic system ${ }^{44}$ and offers further support to an inflammation-based aetiology, as smoking induces an inflammatory response. ${ }^{45}$ Non-steroidal anti-inflammatory drugs and both oral contraceptives and oral hormone therapy have an impact on circulating levels of $\mathrm{CRP}^{30,46}$ and our findings corroborate these reports. Childhood maltreatment predisposes to depression and may play a role in increasing the risk for inflammation in adulthood; ${ }^{47,48}$ this has not been entered into the models, as these data were not available.

We recognise that complex interactions are likely between inflammation, redox status and other factors modulating psychiatric well-being. Moreover, circulating hsCRP levels may be acting as a surrogate for unrecognised confounders that affect the risk for depressive disorders. However, within these constraints, we infer that circulating hsCRP is an independent prognostic marker for major depression in women. As these data pertain predominantly to White women, interpretation may not be generalisable to women of other ethnicities, or to men.

It is evident that diabetes, ${ }^{49}$ cardiovascular disease ${ }^{50}$ and bone fragility ${ }^{51}$ are characterised by systemic inflammation. Depression is commonly reported among patients with these disorders and, although it is possible that hsCRP is simply a marker for these disorders, which in turn may increase the risk for depression, it is also plausible that inflammation could underpin this association. Replicatory studies measuring other cytokines are needed to confirm this notion. C-reactive protein has been shown to be a vascular risk factor in individuals with mental illness. $^{52}$

\section{Summary}

Serum hsCRP appears to be an independent prognostic marker for de novo major depressive disorder risk in women. This supports an 
aetiological role for inflammatory activity in the genesis of depression. In addition, it provides a mechanistic link between depression and commonly comorbid medical disorders, and suggests potential intervention targets.

Julie A. Pasco, BSC(Hons), Dip Ed, PhD, MEpi, Geoffrey C. Nicholson, MBBS, PhD FRACP, FRCP, Lana J. Williams, BPsych, Grad Dip App Psych, PhD, Felice N. Jacka, BA, PgDipSC, PhD, Margaret J. Henry, BSc(Hons), PhD, Mark A. Kotowicz, MBBS, FRACP, The University of Melbourne, Department of Clinical and Biomedical Science, Barwon Health, Geelong, Victoria, Australia; Hans G. Schneider, MD, FRACP, FRCPA Department of Medicine, Monash University, Melbourne, Australia; Brian E. Leonard PhD, DSC, MRIA, Galway Pharmacology Department, National University of Ireland, Galway, Ireland; Michael Berk, MBBch, Mmed, FF(Psych)SA, FRANZCP, PhD, The University of Melbourne, Department of Clinical and Biomedical Science, Barwon Health, Geelong, Victoria, and Orygen Research Centre and Mental Health Research Institute, Australia

Correspondence: Associate Professor Julie A. Pasco, Epidemiology and Biostatistics Unit, Department of Clinical and Biomedical Sciences, Barwon Health, The University of Melbourne, PO Box 281, Geelong 3220, Australia. Email: juliep@barwonhealth.org.au

First received 9 Dec 2009, final revision 21 May 2010, accepted 22 Jul 2010

\section{Funding}

The study was funded by the Victorian Health Promotion Foundation and the National Health and Medical Research Council of Australia.

\section{Acknowledgement}

We thank Sharon Brennan for obtaining the socioeconomic data for the study.

\section{References}

1 Smith RS. The macrophage theory of depression. Med Hypotheses 1991; 35 298-306.

2 Maes M, Bosmans E, Meltzer HY, Scharpe S, Suy E. Interleukin-1 beta: a putative mediator of HPA axis hyperactivity in major depression? Am J Psychiatry 1993; 150: 1189-93.

3 Frommberger UH, Bauer J, Haselbauer P, Fraulin A, Riemann D, Berger M. Interleukin-6-(IL-6) plasma levels in depression and schizophrenia: comparison between the acute state and after remission. Eur Arch Psychiatry Clin Neurosci 1997; 247: 228-33.

4 Mikova O, Yakimova R, Bosmans E, Kenis G, Maes M. Increased serum tumor necrosis factor alpha concentrations in major depression and multiple sclerosis. Eur Neuropsychopharmacol 2001; 11: 203-8.

5 Sluzewska A, Rybakowski J, Bosmans E, Sobieska M, Berghmans R, Maes M, et al. Indicators of immune activation in major depression. Psychiatry Res 1996; 64: 161-7.

6 Berk M, Wadee AA, Kuschke RH, O'Neill-Kerr A. Acute phase proteins in major depression. J Psychosom Res 1997; 43: 529-34.

7 Pepys MB, Baltz ML. Acute phase proteins with special reference to C-reactive protein and related proteins (pentaxins) and serum amyloid $A$ protein. Adv Immunol 1983; 34: 141-212.

8 Deodhar SD. C-reactive protein: the best laboratory indicator available for monitoring disease activity. Cleve Clin J Med 1989; 56: 126-30.

9 Pikhart H, Hubacek JA, Kubinova R, Nicholson A, Peasey A, Capkova N, et al. Depressive symptoms and levels of C-reactive protein: a population-based study. Soc Psychiatry Psychiatr Epidemiol 2009; 44: 217-22.

10 Ford DE, Erlinger TP. Depression and C-reactive protein in US adults: data from the Third National Health and Nutrition Examination Survey. Arch Intern Med 2004; 164: 1010-4.

11 Panagiotakos DB, Pitsavos C, Chrysohoou C, Tsetsekou E, Papageorgiou C Christodoulou G, et al. Inflammation, coagulation, and depressive symptomatology in cardiovascular disease-free people; the ATTICA study. Eur Heart J 2004; 25: 492-9.

12 Danner M, Kasl SV, Abramson JL, Vaccarino V. Association between depression and elevated C-reactive protein. Psychosom Med 2003; 65: 347-56

13 Penninx BW, Kritchevsky SB, Yaffe K, Newman AB, Simonsick EM, Rubin S, et al. Inflammatory markers and depressed mood in older persons: results from the Health, Aging and Body Composition study. Biol Psychiatry 2003: 54: $566-72$.

14 Kop WJ, Gottdiener JS, Tangen CM, Fried LP, McBurnie MA, Walston J, et al Inflammation and coagulation factors in persons $>65$ years of age with symptoms of depression but without evidence of myocardial ischemia. Am J Cardiol 2002; 89: 419-24.

15 Bluthe RM, Michaud B, Poli V, Dantzer R. Role of IL-6 in cytokine-induced sickness behavior: a study with IL-6 deficient mice. Physiol Behav 2000; 70 $367-73$

16 Dutcher J. Current status of interleukin-2 therapy for metastatic renal cell carcinoma and metastatic melanoma. Oncology (Williston Park) 2002; 16 4-10.

17 Dutcher J. High-dose interleukin-2 in metastatic disease: renal cell carcinoma and melanoma. Oncology (Williston Park) 2002; 16: 3

18 Dutcher JP, Logan T, Gordon M, Sosman J, Weiss G, Margolin K, et al. Phase II trial of interleukin 2, interferon alpha, and 5-fluorouracil in metastatic renal cell cancer: a cytokine working group study. Clin Cancer Res 2000; 6 3442-50.

19 Dell'Osso L, Pini S, Maggi L, Rucci P, Del Debbio A, Carlini M, et al. Subthreshold mania as predictor of depression during interferon treatment in $\mathrm{HCV}+$ patients without current or lifetime psychiatric disorders. J Psychosom Res 2007; 62: 349-55.

20 van den Biggelaar AH, Gussekloo J, de Craen AJ, Frolich M, Stek ML, van der Mast RC, et al. Inflammation and interleukin-1 signaling network contribute to depressive symptoms but not cognitive decline in old age. Exp Gerontol 2007; 42: 693-701.

21 Milaneschi Y, Corsi AM, Penninx BW, Bandinelli S, Guralnik JM, Ferrucci L. Interleukin-1 receptor antagonist and incident depressive symptoms over 6 years in older persons: the InCHIANTI Study. Biol Psychiatry 2009; 65: 973-8.

22 Janssen J, Beekman AT, Comijs HC, Deeg DJ, Heeren TJ. Late-life depression: the differences between early- and late-onset illness in a community-based sample. Int J Geriatr Psychiatry 2006; 21: 86-93.

23 Henry MJ, Pasco JA, Nicholson GC, Seeman E, Kotowicz MA. Prevalence of osteoporosis in Australian women: Geelong Osteoporosis Study. J Clin Densitom 2000; 3: 261-8.

24 First MB, Spitzer RL, Gibbon M, Williams JBW. Structured Clinical Interview for DSM-IV-TR Axis I Disorders, Research Version, Non-patient Edition (SCID-I/ NP). Biometrics Research, New York State Psychiatric Institute, 2002.

25 Korn EL, Graubard BI, Midthune D. Time-to-event analysis of longitudinal follow-up of a survey: choice of the time-scale. Am J Epidemiol 1997; 145 72-80.

26 Visser M, Bouter LM, McQuillan GM, Wener MH, Harris TB. Elevated C-reactive protein levels in overweight and obese adults. JAMA 1999; 282 $2131-5$

27 Hak $A E$, Stehouwer CD, Bots ML, Polderman KH, Schalkwijk CG Westendorp IC, et al. Associations of C-reactive protein with measures of adiposity, insulin resistance, and subclinical atherosclerosis in healthy, middle-aged women. Arterioscler Thromb Vasc Biol 1999; 19: 1986-91.

28 Yudkin JS, Stehouwer CD, Emeis JJ, Coppack SW. C-reactive protein in healthy subjects: associations with obesity, insulin resistance, and endothelial dysfunction: a potential role for cytokines originating from adipose tissue? Arterioscler Thromb Vasc Biol 1999; 19: 972-8.

29 Lemieux I, Pascot A, Prud'homme D, Almeras N, Bogaty P, Nadeau A, et al. Elevated C-reactive protein: another component of the atherothrombotic profile of abdominal obesity. Arterioscler Thromb Vasc Biol 2001; 21: 961-7.

30 Raitakari M, Mansikkaniemi K, Marniemi J, Viikari JS, Raitakari OT. Distribution and determinants of serum high-sensitive C-reactive protein in a population of young adults: the Cardiovascular Risk in Young Finns Study. I Intern Med 2005; 258: 428-34.

31 Williams $\sqcup$, Pasco JA, Henry MJ, Jacka FN, Dodd S, Nicholson GC, et al. Lifetime psychiatric disorders and body composition: a population-based study. J Affect Disord 2009; 118: 173-9.

32 Carpenter KM, Hasin DS, Allison DB, Faith MS. Relationships between obesity and DSM-IV major depressive disorder, suicide ideation, and suicide attempts: results from a general population study. Am J Public Health 2000: 90: 251-7.

33 Kloiber S, Ising M, Reppermund S, Horstmann S, Dose T, Majer M, et al. Overweight and obesity affect treatment response in major depression. Biol Psychiatry 2007; 62: 321-6.

34 Reichenberg A, Yirmiya R, Schuld A, Kraus T, Haack M, Morag A, et al. Cytokine-associated emotional and cognitive disturbances in humans. Arch Gen Psychiatry 2001; 58: 445-52.

35 Tiemeier $\mathrm{H}$, Hofman A, van Tuijl HR, Kiliaan AJ, Meijer J, Breteler MM. Inflammatory proteins and depression in the elderly. Epidemiology 2003; 14 $103-7$ 
36 Kuo HK, Yen CJ, Chang $\mathrm{CH}$, Kuo CK, Chen JH, sorond F. Relation of C-reactive protein to stroke, cognitive disorders, and depression in the general population: systematic review and meta-analysis. Lancet Neurol 2005; 4 $371-80$

37 Berk M, Ng F, Dean O, Dodd S, Bush Al. Glutathione: a novel treatment target in psychiatry. Trends Pharmacol Sci 2008; 29: 346-51.

38 Berk M. Oxidative biology: new intervention opportunities in psychiatry. Acta Neuropsychiatrica 2007; 19: 259-60.

39 Galecki P, Szemraj J, Bienkiewicz M, Zboralski K, Galecka E. Oxidative stress parameters after combined fluoxetine and acetylsalicylic acid therapy in depressive patients. Hum Psychopharmacol 2009; 24: 277-86.

40 Wei YC, Zhou FL, He DL, Bai JR, Hui LY, Wang XY, et al. The level of oxidative stress and the expression of genes involved in DNA-damage signaling pathways in depressive patients with colorectal carcinoma. J Psychosom Res 2009; 66: 259-66.

41 Barry S, Clarke G, Scully P, Dinan TG. Kynurenine pathway in psychosis: evidence of increased tryptophan degradation. J Psychopharmacol 2009; 23 287-94.

42 Pasco JA, Williams L, Jacka FN, Ng F, Henry MJ, Nicholson GC, et al. Tobacco smoking as a risk factor for major depressive disorder: population-based study. Br J Psychiatry 2008; 193: 322-6.

43 Hamalainen J, Kaprio J, Isometsa E, Heikkinen M, Poikolainen K, Lindeman S, et al. Cigarette smoking, alcohol intoxication and major depressive episode in a representative population sample. J Epidemiol Community Health 2001; 55: 573-6.

44 Malhi GS, Berk M. Does dopamine dysfunction drive depression? Acta Psychiatr Scand 2007; 115 (suppl 433): 116-24.
45 Kangavari S, Matetzky S, Shah PK, Yano, J, Chyu KY, Fishbein MC, et al. smoking increases inflammation and metalloproteinase expression in human carotid atherosclerotic plaques. J Cardiovasc Pharmacol Ther 2004; 9: 291-8.

46 Blumenfeld Z, Boulman N, Leiba R, Siegler E, Shachar S, Linn R, et al. High C-reactive protein levels are associated with oral hormonal menopausal therapy but not with intrauterine levonorgestrel and transdermal estradiol. Scand J Clin Lab Invest 2007; 67: 257-63.

47 Danese A, Pariante CM, Caspi A, Taylor A, Poulton R. Childhood maltreatment predicts adult inflammation in a life-course study. Proc Natl Acad Sci USA 2007; 104: 1319-24.

48 Danese A, Moffitt TE, Pariante CM, Ambler A, Poulton R, Caspi A. Elevated inflammation levels in depressed adults with a history of childhood maltreatment. Arch Gen Psychiatry 2008; 65: 409-15.

49 Yuan G, Zhou L, Tang J, Yang Y, Gu W, Li F, et al. Serum CRP levels are equally elevated in newly diagnosed type 2 diabetes and impaired glucose tolerance and related to adiponectin levels and insulin sensitivity. Diabetes Res Clin Pract 2006; 72: 244-50.

50 Danesh J, Wheeler JG, Hirschfield GM, Eda S, Eiriksdottir G, Rumley A, et al. C-reactive protein and other circulating markers of inflammation in the prediction of coronary heart disease. N Engl J Med 2004; 350: 1387-97.

51 Pasco JA, Kotowicz MA, Henry MJ, Nicholson GC, Spilsbury HJ, Box JD, et al. High-sensitivity $\mathrm{C}$-reactive protein and fracture risk in elderly women. JAMA 2006; 296: 1353-5.

52 Nilsson K, Gustafson L, Hultberg B. C-reactive protein: vascular risk marker in elderly patients with mental illness. Dement Geriatr Cogn Disord 2008; 26: 251-6.

\section{extra Destigmatising mental illness, House style}

\section{Shabbir Amanullah}

David Shore and Paul Attanasio have done for mental health what many public education series have not been able to do: tackle stigma head on.

By portraying a narcissistic individual with brilliant diagnostic skills and an ability to say what many on occasion would like to but don't for fear of losing their licence, Hugh Laurie made House one of the most popular of TV serials. His character is a potent combination of genius and anger admired by all. 'He got it right, didn't he?'

House's breakdown and hospital admission showed how mental illness can affect anyone and, maybe more likely, the brilliant. Movies like Rain Man and A Beautiful Mind had an impact but mainly on those who identified with mental illness, because of either the nature of their work or personal circumstances. These movies were illness-based and to some extent predictable. House, on the other hand, by depicting a 'normal' physician becoming ill has comfortably punctured the 'will always be ill' myth. Recovering physicians fear being treated 'differently'. They often wonder how it would have been if they were admitted to the local psychiatric unit.

One Flew over the Cuckoo's Nest left an indelible negative image of psychiatry and how mental illness is treated and such a clear depiction of treatability combined with a fresh doctor-patient interface was long overdue. It may be early days to study the impact House's admission and treatment has had on the public but we should capitalise on this and target the stigma that resides within and then without.

As a physicians' body, we must strive to dispel myths about mental illness making the person 'incompetent'. Nothing can be farther from the truth - even House agrees! 